\title{
Chronic Lymphocytic Leukemia Associated with Nephrotic Syndrome and Dermatomyositis
}

\author{
Takashi IshidA*,**, Keiko AirawA***, Takashi TAmurA***, Kouki YoshidA***, \\ Chikara Mikuni***, Masahiro FuIITA****, Hiroshi Isobe** and Yoshikazu KawaKami**
}

Several types of autoimmune complications of chronic lymphocytic leukemia (CLL) have been previously reported. However, the tendency to develop autoantibodies is usually restricted to the hematopoietic system. We report a 68-year-old man who had developed dermatomyositis after ten years of chemotherapy for CLL. He also had secondary nephrotic syndrome at the onset of CLL. Subsequently, the patient died of perforation of the small intestine. The association of both nephrotic syndrome and dermatomyositis with CLL is very rare. We discuss the possibility of a causal relation.

(Internal Medicine 34: 15-17, 1995)

Key words: collagen disease, malignancy, intestinal perforation

\section{Introduction}

Patients with chronic lymphocytic leukemia (CLL) are sometimes complicated with secondary nephrotic syndrome $(1,2)$ and occasionally autoimmune disorders. However, the autoimmune complications of CLL are restricted to the hematopoietic system such as autoimmune hemolytic anemia and autoimmune thrombocytopenia. We report a rare case of Bcell CLL associated with dermatomyositis that appeared ten years after the onset of CLL. This case was also initially complicated with nephrotic syndrome.

\section{Case Report}

A 68-year-old Japanese man was admitted on November 29, 1983, to Sapporo National Hospital complaining of systemic edema. He had been medicated for hypertension for eight years prior to admission, but he had no history of renal disorders. He had no relatives with autoimmune disease.

On admission, the liver, spleen and surface lymph nodes were not palpable. Laboratory investigation showed severe proteinuria (more than $20 \mathrm{~g} /$ day), and hypoproteinemia ( $48 \mathrm{~g} /$ 1). The WBC count was $42.8 \times 10^{9} / 1$ with $83 \%$ small mature lymphocytes (Fig. 1). Using a monoclonal antibody, the lymphocytes were defined as positive for CD5, pan B-cell antibody (L26), HLA-DR and cell surface membrane immunoglobulins $\mu, \delta$, and $\kappa$, and negative for CD3 and CD8. Renal biopsy was not performed.

Under the diagnosis of CLL associated with secondary nephrotic syndrome, treatment with a combination of cyclophosphamide and prednisolone was started. Two months after the chemotherapy, proteinuria disappeared. He was discharged, and he was medicated with chlorambucil for ten years without complications.

On October 8, 1993, he was re-admitted because of weakness and tenderness of the proximal limb muscles. There were brown pigmented lesions on the neck, forehead, shoulders, and front and back of the upper chest. No lymph node enlargement or hepatosplenomegaly was palpable. Laboratory evaluation revealed a marked rise of creatine kinase $(11,015 \mathrm{IU} / 1,99.5 \%$ of MM form isozyme). The WBC count was $11.0 \times 10^{9} / 1$ with $33 \%$ CD5-positive lymphocytes. Proteinuria was absent and autoantibody series (anti-DNA, RNP, Sm, SS-a, SS-b, Jo-1, Scl-70) were all negative. Skin biopsy of the forehead showed slight edema in the dermis and perivascular lymphocytic infiltration, indicating dermatomyositis (Fig. 2). The infiltrating lymphocytes to the skin were defined as negative for CD5 by immunohistochemical staining.

We started treatment with prednisolone at a dose of $60 \mathrm{mg}$ per day. The weakness and tenderness of his muscles were

From the *the Division of Hematology, Sapporo National Hospital, Sapporo (at time of study), **the First Department of Medicine, Hokkaido University School of Medicine, Sapporo, ***the Division of Hematology, Sapporo National Hospital, Sapporo and ****the Division of Clinical Pathology, Sapporo National Hospital, Sapporo

Received for publication March 25, 1994; Accepted for publication September 7, 1994

Reprint requests should be addressed to Dr. Takashi Ishida, the First Department of Medicine, Hokkaido University School of Medicine, Kita 15-jo, Nishi 7-chome, Kita-ku, Sapporo 060 


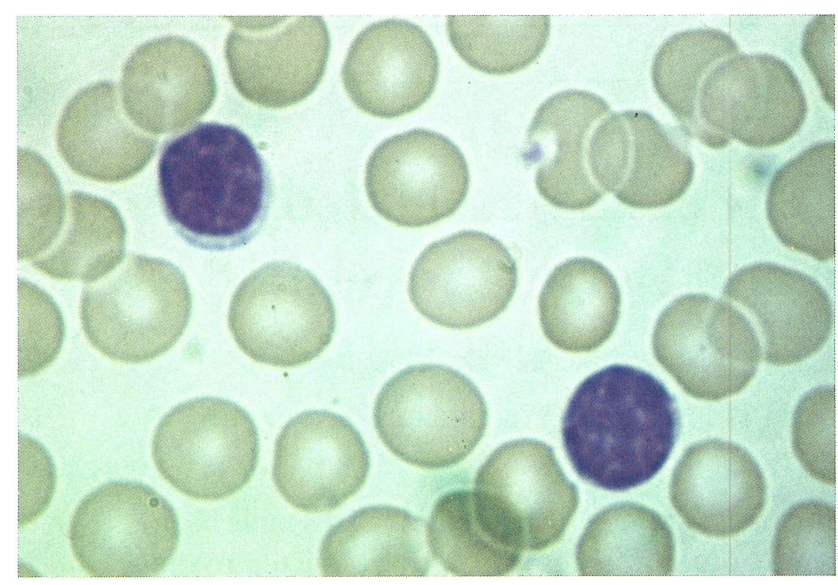

Fig. 1. Leukemic cells seen in peripheral blood. They resembled small mature lymphocytes (May-Giemsa stain, $\times 1,000$ ).

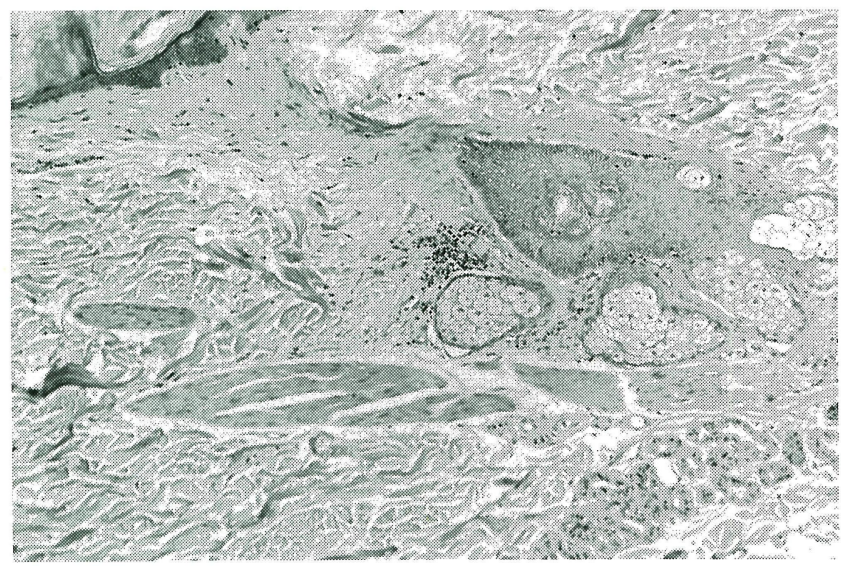

Fig. 2. Skin biopsy of the forehead. Slight edema in the dermis and perivascular lymphocytic infiltration were seen. These changes were not specific, but compatible with dermatomyositis (HE stain, $\times 40$ ).

completely improved in a few days. On the morning of October 18, 1992 (the ninth day of administration of prednisolone), he suddenly went into shock and died.

Autopsy revealed a perforation of the small intestine with purulent ascites in the peritoneal cavity and ulcerations in the sigmoid colon. Microscopically, infiltration of leukemic cells was confirmed in those lesions (Fig. 3). In the spleen, a leukemic cell mass $(2 \mathrm{~cm}$ in diameter) was also present. The skeletal muscle showed degeneration of muscle fibers and interstitial inflammatory infiltration (Fig. 4). The cells infiltrating the muscle were not leukemic lymphocytes. Each glomerulus was almost intact and no deposit of either $\operatorname{IgG}, \operatorname{IgA}, \operatorname{IgM}, \mathrm{C}_{3}$ or $\mathrm{C}_{4}$ were proved with immunofluorescence method. We confirmed the presence of Enterococcus faecalis and Proteus vulgaris in a culture of the ascites. No other malignancy was present.

\section{Discussion}

CLL patients may develop various autoimmune phenom-

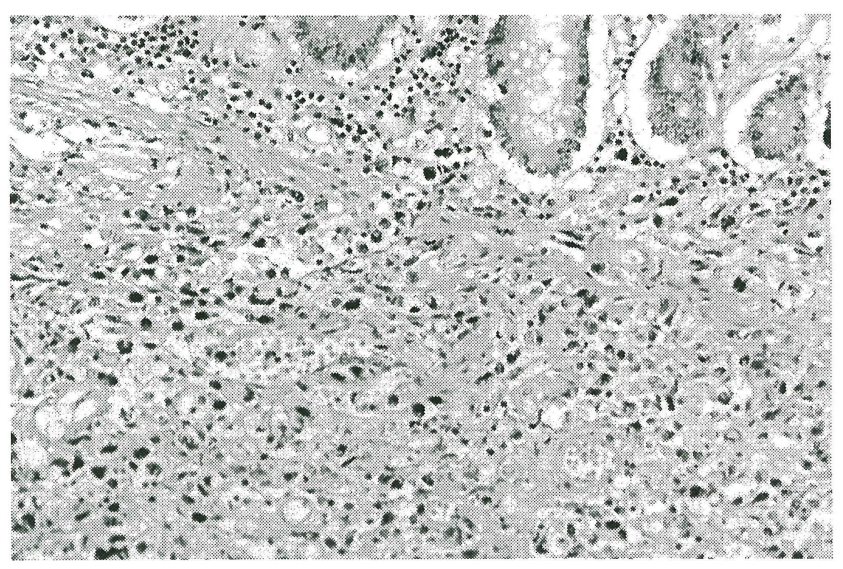

Fig. 3. Infiltration of leukemic cells in the submucosa of the perforated intestinal lesion (HE stain, $\times 200$ ).

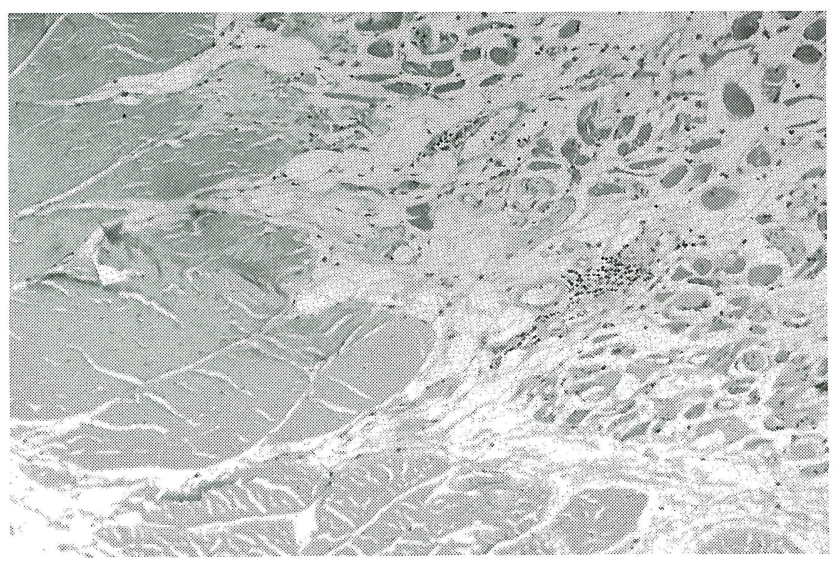

Fig. 4. Skeletal muscle with interstitial inflammatory infiltration. Degeneration of muscle fibers was also observed (HE stain, $\times 40$ ).

ena, especially hematopoietic disorders such as thrombocytopenia and hemolytic anemia. The occurrence of nonhematological autoimmune diseases is very rare during the course of CLL. Some authors have reported the association of hyperthyroidism (3), cold urticaria with cryoglobulinemia (4), and dermatomyositis $(5,6)$. In this case, nephrotic syndrome and dermatomyositis were observed during the course of CLL over a ten-year period.

Although the immune function in CLL patients is reduced, the reason as to why the patients develop autoimmune disorders is unclear. In most cases of CLL, the leukemic cells are CD5positive $\left(\mathrm{CD}^{+}\right) \mathrm{B}$-lymphocytes. $\mathrm{CD}^{+} \mathrm{B}$-cells are suggested to be involved in some autoimmune diseases. $\mathrm{CD}^{+} \mathrm{B}$-cells in peripheral blood are elevated in rheumatoid arthritis, Sjögren syndrome, progressive systemic sclerosis (7), and immune thrombocytopenic purpura (8). To our knowledge, however, the association of $\mathrm{CD}^{+} \mathrm{B}$ cells and dermatomyositis has not been reported. Although the relationship between $\mathrm{CD} 5^{+} \mathrm{B}$-cells and T-cells is also unclear, reduced numbers of T-helper cells 
and correspondingly increased numbers of T-suppressor cells have been reported in CLL patients (9). Thus, one possible hypothesis is that autoimmune phenomena are caused by an imbalance of T-cell subsets (10). On the other hand, $\mathrm{CD}^{+} \mathrm{B}$ cells are not elevated in the peripheral blood of patients with systemic lupus erythematosus (SLE). Interestingly, high-affinity autoantibodies to ssDNA are produced by CD5-negative Bcells (11). In New Zealand mice which are prone to develop SLE or CLL spontaneously, the major histocompatibility haplotype may predispose either to SLE or to CLL (12).

The frequency of nephrotic syndrome in patients with CLL is estimated to be less than 1 to $2 \%$ (1). Membranoproliferative glomerulonephritis (MPGN) related to the immunocomplex is thought to be the most common glomerular lesion. Minimal change is another major form of glomerular disease (1), which is suspected to be related to cytokines produced by abnormal Tlymphocytes. The cytokines may alter the selectivity of permeability characteristics of the glomerular basement membrane (2).

In the present case, minimal change rather than MPGN was suspected to have been present because specific changes were not seen at autopsy. $\mathrm{CD}^{+} \mathrm{B}$-cell malignant clones did not directly act to produce autoantibodies, giving negative findings for autoantibody series. Besides abnormal functions of lymphocytes, alkylating agents might play a role in autoimmune phenomena (13). However, the exact mechanism of autoimmune complications is unknown. Abnormal T-cell function may have been the cause of not only nephrotic syndrome but also dermatomyositis in our patient. As CLL is not so common in Japan, further accumulation of similar cases may help us to understand the relationship of this disease to autoimmune complications.

\section{References}

1) Seney FD, Warren RF, Stein H, Kashgarian M. A review of nephrotic syndrome associated with chronic lymphocytic leukemia. Arch Intern Med 146: 137, 1986.

2) Alpers CE, Cotran RS. Neoplasia and glomerular injury. Kidney Int 30: $465,1986$.

3) Haubenstock A, Zalusky R. Autoimmune hyperthyroidism and thrombocytopenia developing in a patient with chronic lymphocytic leukemia. Am J Hematol 19: 281, 1985.

4) Rawnsley HM, Shelley WB. Cold urticaria with cryoglobulinemia in a patient with chronic lymphocytic leukemia. Arch Dermatol 98: 12, 1968.

5) Lischner M, Prokocimer M, Zolberg A, Shaklai M. Autoimmunity in chronic lymphocytic leukaemia. Postgrad Med J 64: 590, 1988.

6) Salvi A, Franceschini R, Balestrieri GP, Maroccolo M, Spandrio S Giustina G. Polymyositis associated with chronic lymphocytic leukemia. Clin Exp Rheumatol 9: 209, 1991.

7) Hardy RR, Hayakawa K, Shimizu M, Yamasaki K, Kishimoto T. Rheumatoid factor secretion from human Leu- ${ }^{+}$B cells. Science 236: 81 , 1987.

8) Mizutani H, Furubayashi $\mathrm{T}$, Kashiwagi $\mathrm{H}$, et al. B cells expressing CD5 antigen markedly increased in peripheral blood and spleen lymphocytes from patients with immune thrombocytopenic purpura. Br J Haematol 78: 474, 1991.

9) Catovsky D, Lauria F, Matutes E, et al. Increase in T lymphocytes in B cell chronic lymphocytic leukaemia. Br J Haematol 47: 539, 1981.

10) Kay NE. Abnormal T cell subpopulation function in CLL: excessive suppressor $\mathrm{T}$ and deficient helper $\mathrm{T}$ activity with respect to $\mathrm{B}$ cell proliferation. Blood 57: 418, 1981.

11) Casali P, Burastero SE, Balow JE, Notkins AL. High affinity autoantibodies to ssDNA are produced by $\mathrm{CD}^{-} \mathrm{B}$ cells in systemic lupus erythematosus patients. J Immunol 143: 3476, 1989.

12) Okada T, Takiura F, Tokushige $\mathrm{K}$, et al. Major histocompatibility complex controls clonal proliferation of $\mathrm{CD}^{+} \mathrm{B}$ cells in $\mathrm{H}$-2-congenic New Zealand mice: a model for B cell chronic lymphocytic leukemia and autoimmune disease. Eur J Immunol 21: 2743, 1991

13) Lewis FB, Schwartz RS, Dameshek W. X-radiation and alkylating agents as possible 'trigger' mechanisms in the autoimmune complications of malignant lymphoproliferative disease. Clin Exp Immunol 1: 3, 1966. 